\title{
Geoecologia das Paisagens: uma análise cienciométrica da sua produção científica no Brasil (1990 - 2019)
}

Landscape Geoecology: a scientometric analysis of its scientific production in Brazil (1990 - 2019)

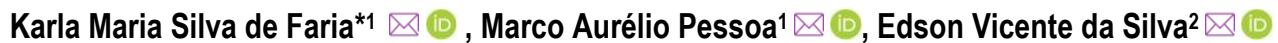 \\ 1 Instituto de Estudos Socioambientais, Universidade Federal de Goiás, Goiânia, Goiás, Brasil \\ 2Departamento de Geografia, Universidade Federal do Ceará, Fortaleza, Ceará, Brasil \\ Recebido (Received): 13/11/2020 \\ E-mail: mpessoa@ufg.br (MAP); cacauceara@gmail.com (EVS) \\ *E-mail para correspondência: karla_faria@ufg.br
}

Resumo: A análise cienciométrica permite avaliar o desenvolvimento de produção científica, as tendências e o crescimento do conhecimento em uma área específica. Diante da emergência de pesquisas na área ambiental, a Geoecologia das Paisagens, sustentada em princípios teóricos e metodológicos de análise sistêmica da paisagem, se soma as demais disciplinas de atuação das ciências com abordagem interdisciplinar. O objetivo deste estudo foi analisar o desenvolvimento do conhecimento científico sobre Geoecologia no Brasil, avaliando a distribuição das pesquisas por regiões e centros de pesquisa e a influência dos grupos de pesquisa na consolidação dessa linha de estudo. Os procedimentos metodológicos envolveram análise quantitativa da produção científica obtida nas bases de dados de teses e dissertações brasileiras e artigos científicos em distintas bases, que foram tratados em análise estatísticas para traçar o perfil da linha temática da pesquisa e a posição dos principais autores que contribuem para desenvolvimento do conhecimento científico. Os registros relacionados a defesas por ano, por instituições e dos artigos indicam a existência de dois recortes temporais (antes e depois de 2010); as publicações e pesquisas demonstram a diversidade de pesquisas nas regiões brasileiras e o destaque de instituições de ensino superior e pesquisadores no Sudeste e no Nordeste. Os grupos de pesquisa existentes no Nordeste exercem maior influência no desenvolvimento do conhecimento científico da Geoecologia das Paisagens, tendo uma predominante aplicação para o zoneamento ambiental e territorial.

Palavras chave: Análise sistêmica da paisagem; zoneamento; planejamento; grupos de pesquisa brasileiros.

Abstract: The scientometric analysis allows to evaluate the scientific production development, the tendencies and knowledge growth in a specific area. In the face of the emergence of research in the environmental area, Landscapes Geoecology, based on theoretical and methodological principles of systemic landscape analysis, adds to others disciplines of science activity with an interdisciplinary approach. The objective was to analyze the development of scientific knowledge about Geoecology in Brazil, evaluating the distribution of research by regions and research centers and the influence of research groups in the consolidation of this line of study. The methodological procedures involved quantitative analysis of the scientific production obtained from the databases of Brazilian theses and dissertations and scientific papers in different bases, which were treated in statistical analysis to outline the profile of the thematic line of the research and the position of the main authors who contribute to development of scientific knowledge. The records related to defenses by year, by institutions and by scientific papers indicate the existence of two time cutouts (before and after 2010); publications and researches demonstrate the diversity of researches in Brazilian regions and the featured of higher education institutions and researchers in the southeast and northeast. The research groups in the northeast presents a greater influence on the scientific knowledge development of Landscape Geoecology, having a predominant application for environmental and territorial zoning.

Kaywords: Systemic landscape analysis; zoning; planning; Brazilian research groups. 


\section{Introdução}

As pesquisas sobre o Estado da Arte, Estado do Conhecimento ou Cienciometria surgiram na década de 1960, quando a Organização das Nações Unidas para a Educação, a Ciência e a Cultura (Unesco), junto com a Organização para a Cooperação e Desenvolvimento Econômico (OCDE), começaram a desenvolver metodologias de avaliação da produção científica e tecnológica (SPINAK, 1998; BITTENCOURT; PAULA, 2012). A necessidade de avaliação da produção, sistematização dos conhecimentos e compreensão da evolução da ciência têm sido as principais defesas da Cienciometria (BORNMANN; LEYDESDORFF, 2014). Nas últimas décadas, este tipo de pesquisa tem crescido no Brasil (CARDOSO et al., 2005; FARIA; ALVES, 2016; PARRA et al., 2019; SILVA FILHO, 2019) e em demais países, justificados pelo volume da produção científica e pelo avanço das novas tecnologias, com criações de bases de dados virtuais e, consequentemente, ampliação do acesso à informação.

A cienciometria pode ser definida como a análise quantitativa da produção científica que demanda a agregação de diferentes indicadores que irão identificar as tendências e o crescimento do conhecimento em uma área, avaliar os aspectos estatísticos da linguagem (das palavras e das frases), medir o crescimento de determinadas áreas, e o surgimento de novos temas (TAGUE-SUTCKIFFE, 1992; VINKLER, 2006; VANTI, 2002; LEYDESDORFF, 2004). O ordenamento de informações e resultados permitem não apenas mapear, constituir uma base de dados, difundir e dar publicidade aos conhecimentos produzidos, mas, principalmente, possibilita identificar lacunas e contradições, apontando novos caminhos de investigação (PARRA et al., 2019).

No âmbito desses pontos de vista a serem estudados, a emergência social, econômica e ambiental decorrente da crise ambiental influenciam estratégias e modelos de desenvolvimento baseados em uma perspectiva sustentável e de compreensão integrada. Este cenário corresponde a um paradigma da relação exploratória da sociedade para com o meio natural (a natureza). Conforme Rodriguez e Silva (2002, p.95) romper com esse paradigma envolve embasamentos teóricos e metodológicos, sustentados "em visões holísticas, integradoras e sistêmicas das unidades ambientais naturais e sociais". Trata-se de compreender a natureza interdisciplinar e sistêmica de processos naturais, sociais e culturais, dentre eles o estudo de paisagens.

O estudo das paisagens naturais envolve dois direcionamentos teóricos: $1^{\mathbf{0}}$ voltado para os aspectos biofísicos, de base epistemológica fincada na geografia alemã de Humboldt e Dokuchaev, a qual fundamentou também os estudos da geografia russo-soviética, com um viés mais naturalista; e $2^{\circ}$ voltado ao sociocultural, sob o qual se analisa a paisagem a partir da ótica social ou pela percepção humana (RODRIGUEZ et al., 2013). A Geoecologia das Paisagens busca, portanto, integrar estes dois direcionamentos teórico-metodológicos sobre a abordagem da paisagem no contexto integrado da Geografia com a Ecologia, concentrando-se nos estudos Geoecológicos, Ecogeográficos e da Geografia Ambiental.

O campo de abordagem da paisagem apresentado pela Geoecologia das Paisagens tem seus fundamentos teóricos e metodológicos inseridos em uma perspectiva de análise sistêmica (RODRIGUEZ et. al., 2013). Sua estruturação científica foi proposta em 1939 por Karl Troll, inicialmente denominada de Ecologia da Paisagem e, posteriormente, em 1966, de Geoecologia das Paisagens, como uma ciência com propósito de análise das relações complexas entre os componentes naturais e da inter-relação entre os seres vivos e seu ambiente (SIQUEIRA et al., 2013).

Como apresentado por Metzger (2001) essa emergente disciplina distingue duas abordagens: a geográfica, que destaca o estudo da influência do homem sobre a paisagem e a gestão do território; e a ecológica, que ressalta a importância do contexto espacial sobre os processos ecológicos em termos de conservação biológica.

A Geoecologia das Paisagens se soma a outras abordagens da Geografia e de outras ciências na proposição ativa e interdisciplinar das questões ambientais e socioeconômicas (JANISE; LEONARDO, 2007). É uma abordagem que se dedica a análises para o planejamento ambiental e territorial que evolui da perspectiva sistêmica para a geossistêmica apresentada por Sotchava na década de 1960, e que visa a regionalização de unidades homogêneas que representam a influência de fatores naturais e antropogênicos (RODRIGUEZ, SILVA; CAVALCANTE, 2007).

Dedica-se, portanto, na análise da inter-relação dos aspectos estrutural-espacial e dinâmico-funcional das paisagens como subsídio aos sistemas socioeconômicos que exploram o potencial ecológico da paisagem, por meio do diagnóstico de potencialidades, das limitações e dos problemas ambientais que possam comprometer as funções ambientais por elas desempenhadas (RODRIGUEZ; SILVA, 2013). 
A Ecologia das Paisagens também tem enfoque nas relações entre padrões espaciais com forte incorporação da escala nas análises das unidades "naturais para análise dos processos ecológicos. Embora Metzger (2001) destaque que a escala adotada por essa abordagem seria a correta para responder aos principais problemas ambientais, as pesquisas têm nos últimos anos se dedicado a avaliar os efeitos de fragmentação de habitats, com uso de métricas descritivas da paisagem e robusto tratamento estatísticos, enquanto a Geoecologia da paisagem tem se dedicado ao processo de espacialização, regionalização e tipologias para fins de planejamento.

Dada a multiplicidade de ciências e abordagens na tratativa das questões ambientais emergentes na década de 1990 e crescentes nas décadas seguintes, é essencial avaliar como a ciência, produzida nas universidades brasileiras, contribuiu na evolução e fortalecimento da disciplina Geoecologia das Paisagens. É importante não só para resgate teórico-metodológico, como também para avaliar a evolução e as tendências das pesquisas.

Portanto, o presente trabalho se propõe a analisar o desenvolvimento do conhecimento científico sobre Geoecologia no Brasil, avaliando a distribuição das pesquisas por regiões e centros de pesquisa e a influência dos grupos de pesquisa na consolidação da linha de pesquisa de Geoecologia.

\section{Material e método}

A base metodológica deste artigo é a pesquisa quantitativa da produção científica fundamentada na Cienciometria que compõe as pesquisas sobre "estado da arte" ou "estado do conhecimento" acerca de determinada disciplina ou assunto. A Cienciometria se integra a outros métodos como a bibliometria, a informetria e webometria que avaliam, basicamente, o conteúdo científico já produzido e disponibilizado para consulta. A cienciometria, no entanto, se apoia em indicadores quantitativos e análises estatísticas que traçam um perfil dos campos científicos e a posição dos principais autores e suas representações em ramos do conhecimento (VANTI, 2002). Trata-se de análise multidimensional que requer agregação de diferentes indicadores (VINKLER, 2006).

O objeto de estudo são as pesquisas acadêmicas produzidas em todo o país na forma de artigos completos publicados em periódicos indexados, dissertações e teses, considerando como recorte temático os indexadores "Geoecologia"; "Geoecologia da Paisagem", "Geoecologia das Paisagens", "Geoecologia de Paisagens"; "Geoecológico" e "Geoecológica", que tivessem relação direta com a aplicabilidade da abordagem geoecológica. Para as bases internacionais foram consideradas os indexadores: "Geoecology" e "Landscape Geoecology".

As bases para busca de dados foram vinculadas a repositórios de abrangência nacionais e internacionais e avaliadas segundo cada conjunto de dados:

(1) para o conjunto de dados acadêmicos relacionados a dissertações e teses priorizou-se os disponíveis na Biblioteca Digital Brasileira de Teses e Dissertações (BDBTD) (http://bdtd.ibict.br/vufind/) e no Catálogo da Coordenação de Aperfeiçoamento de Pessoal de Nível Superior (Capes) (https://catalogodeteses.capes.gov.br/catalogo-teses/\#!/);

(2) para o conjunto de dados de artigos/papers, inicialmente os acessos foram realizados nas bases do Portal de Periódico da Capes (http://www.periodicos.capes.gov.br/); Directory of Open Access Journals (DOAJ) (https://doaj.org/), Sistema de Información Científica de Revistas Científicas (Redalyc) (https://www.redalyc.org/revista.oa?id=3371), Scientific Electronic Library Online (Scielo) (https://scielo.org/) e Web of Science (www.webofknowledge.com). O baixo quantitativo de artigos nas bases iniciais demandou a expansão e inclusão de artigos disponibilizados no Google acadêmico (https://scholar.google.com.br/?hl=pt) e ainda na Plataforma Lattes (http://lattes.cnpq.br/), adotando como critério dentro da plataforma, a avaliação individual do currículo dos pesquisadores responsáveis por orientação de Teses e Dissertações sobre a temática dos indexadores. O mapeamento nessas plataformas possibilitou a busca de literatura cinza.

O recorte temporal selecionado foi de 1997 a 2019, sendo que 1997 representa o ano dos primeiros registros com a abordagem da Geoecologia em pesquisas científicas nas universidades brasileiras. Como as plataformas não possuem o mesmo padrão para refinamento de inclusão/exclusão de indexadores, para garantir unanimidade no tratamento dos artigos, teses e dissertações indicados pelas plataformas, houve a necessidade de realizar triagens de exclusão e verificação manual, avaliando se o teor teórico e metodológico estava vinculado aos princípios da Geoecologia das Paisagens. 
Durante esse procedimento manual, foram realizadas as eliminações de arquivos duplicados, checagem de consistência das pesquisas, com aplicação de dois filtros, sendo: (i) filtro com a avaliação do título e resumo para os dois conjuntos de dados e (ii) filtro envolvendo a verificação nas teses, dissertações e artigos do detalhamento teórico e metodológico. A aplicação desses dois filtros foi realizada mediante a leitura dos arquivos e organização para disponibilização em banco de dados digital sobre a temática no site do Laboratório de Geomorfologia, Pedologia e Geografia Física (LABOGEF) - https://labogef.iesa.ufg.br/.

Como as pesquisas de Geoecologia têm abrangência na área ambiental com forte integração em análises e pesquisas interdisciplinares, a busca foi ampla para todas as áreas de conhecimento científico estabelecidas na CAPES e no CNPq.

Priorizou-se, para análise cienciométrica e para o atendimento do objetivo desta pesquisa a organização dos dados relacionados a ano de defesa e da publicação; região do Programa de Pós-Graduação e vínculo do artigo com pesquisa de pós-graduação e Agências Financiadoras; base indexadora dos artigos; Área de Conhecimento do PPG e Tipo/Nível de Pesquisa; vinculo do orientador e dos autores com grupo de pesquisa cadastrado no CNPq sobre a temática, Fator de impacto da Journal Citation Reports (JCR) - Com ou sem JCR e score de classificação dos periódicos na base do qualis.

A avaliação do vínculo profissional do orientador ao grupo de pesquisa cadastrado no CNPq sobre a temática visa avaliar a articulação e o fortalecimento da Geoecologia como uma linha de pesquisa científica e o uso do Journal Citation Reports (JCR), como indicador de classificação da divulgação internacional das revistas e, consequentemente, das publicações.

Na etapa de pré-análise das palavras-chave constatou-se a existência de variações semânticas e distintas abordagens teóricas entre os pesquisadores. A fim de padronizar a análise, realizou-se redução de descritores/termos em 7 agrupamentos que consideraram a semântica e relações entre os descritores.

O conjunto de dados de cada grupo foi avaliado individualmente, comparativamente e quantitativamente com análise estatística nos softwares R e Statistica.

\section{Resultados e discussão}

As consultas nas bases de dados indicaram um universo amostral de 852 arquivos, sendo 136 documentos referentes a literatura cinza (teses e dissertações) e 716 artigos em periódicos nas bases de indexadores utilizadas. Após a aplicação dos filtros para avaliação dos documentos quanto aos critérios para inclusão e exclusão, o universo amostral foi reduzido para 195 documentos aptos para análise. Deste segundo universo de dados, 120 trabalhos correspondiam a teses (49 documentos) e dissertações (72 documentos) e 102 aos artigos (Figura 1).

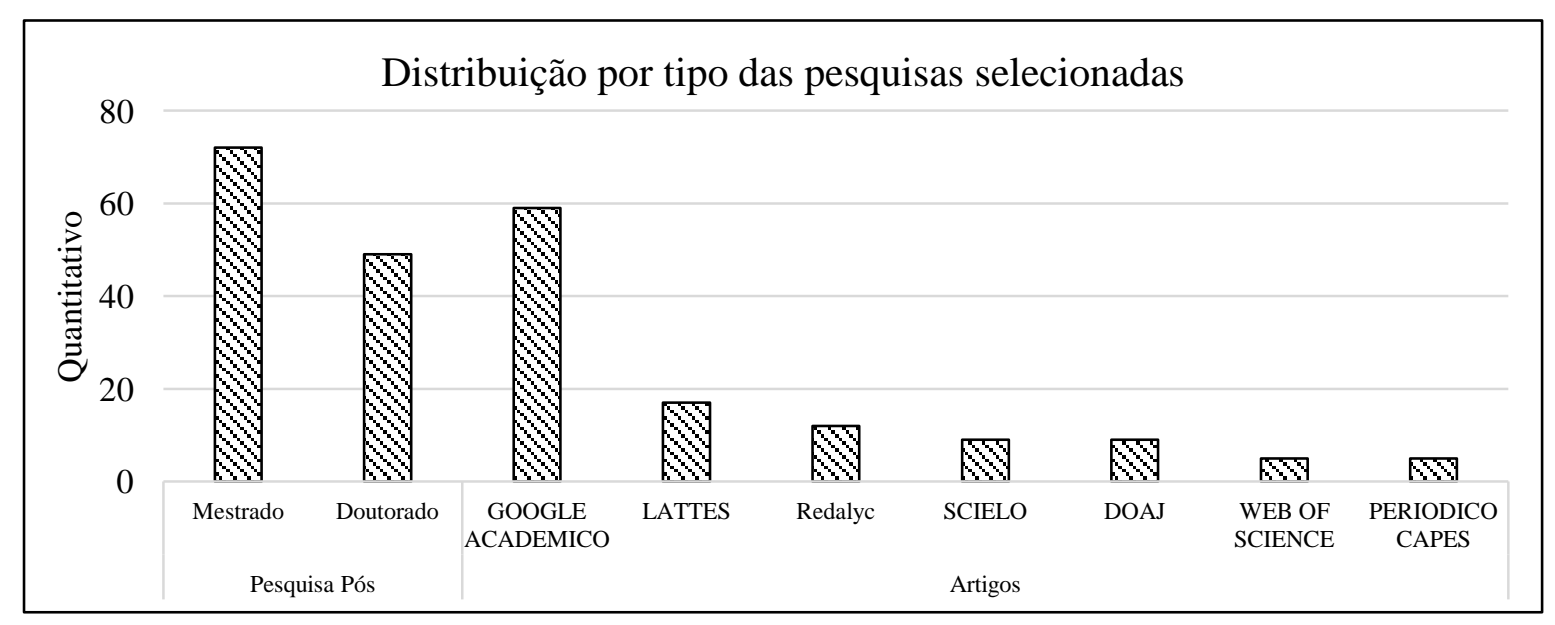

Figura 1: Distribuição das pesquisas por base de dados. Fonte: Bases de dados. Organização: Autores, 2020.

Dentro do recorte temático e temporal, as dissertações correspondem a $60 \%$ do universo de pesquisas acadêmicas, e, entre os artigos, o maior percentual (33\% da amostragem) foi localizado na base do Google Acadêmico. Destaca-se que na base do Google Acadêmico foram identificados 279 artigos, mas após os procedimentos de inclusão e exclusão e correlação com artigos presentes nas outras bases de dados, apenas 
59 artigos apresentam exclusividade. Trata-se de uma base "democrática" que permitiu acesso a artigos em revistas que não se incluem aos portais científicos de buscas usuais e atuais.

Deve ser realizada uma ressalva quanto ao quantitativo de trabalhos acadêmicos em nível de teses e dissertações. Os indexadores utilizados podem ter limitado a busca dentro dos portais de teses e dissertações da Capes e da Biblioteca Digital Brasileira de Teses e Dissertações (BDTD), pois na base da CAPES, para os trabalhos defendidos anteriormente à Plataforma Sucupira, só foi possível avaliar a existência dos indexadores presentes no título, pois não é disponibilizado acesso aos resumos e palavras chaves. Assim, se o título não apresentava nenhum dos indexadores, o trabalho acabou não sendo selecionado para avaliação. No caso de publicações anteriores à Plataforma, foi realizada uma busca manual pelo documento; aqueles que foram encontrados, foram avaliados e os que não foram localizados, foram mantidos na amostragem por terem apresentado indexador no título.

Infere-se, ainda, que fatores como alimentação incorreta da plataforma, a não inserção de pesquisas e programas de pós-graduação extintos antes da organização do catálogo podem ter contribuído para o universo amostral encontrado para teses e dissertações. Na base do BDTD, o problema pode residir na ausência de ligação com os repositórios digitais das universidades.

Quanto aos artigos também é necessário destacar que as revistas devem pleitear a vinculação aos portais indexadores e somente após o atendimento de critérios específicos é que os artigos passam a ficar vinculados e disponibilizados. Portanto, as publicações anteriores a esse processo não são apontadas pela base indexadora. Sendo assim, a análise dos dados identificou concentração de pesquisas sobre a temática exclusivamente no Google Acadêmico e não nos portais indexadores. O baixo quantitativo de artigos nos mais conhecidos de indexadores de abrangência temática geral, como o SciELO (nacional), a Web of Science e a SCOPUS (internacionais), pode influenciar na limitação do alcance e publicização internacional das pesquisas desenvolvidas sobre a abordagem no Brasil, mesmo de artigos publicados em inglês.

\subsection{Análise de literatura cinza - dissertações e teses}

A discussão científica sobre a temática da sustentabilidade, que ganhou força na década de 1990, contribuiu para o desenvolvimento teórico e metodológico de diversas ciências que se dedicam a temáticas ambientais. E para aqueles que os estudos da paisagem e seus diferentes aspectos são sustentados em bases teóricas e metodológicas da Geoecologia das Paisagens, houve maior frequência, inclusive a abordagem e o tratamento dos processos passaram a ser enriquecidos com as contribuições do pensamento dialético na análise espacial e ambiental (RODRIGUEZ; SILVA, 2006).

As análises realizadas no campo da Geoecologia das Paisagens incorporam a sustentabilidade no processo de desenvolvimento, oferecendo, por meio do planejamento, contribuições importantes para o conhecimento da base natural e do meio ambiente (BARROS, 2011). Conforme a avaliação dos dados, constata-se que o registro oficial mais antigo corresponde a tese de doutorado do ano de 1997 na Universidade Federal do Rio do Janeiro (UFRJ), que já apresentava abordagem da Geoecologia para análise de modelos de planejamento de zoneamentos territorial-ambiental.

A distribuição do número de defesas por ano indica o comportamento das pesquisas relacionadas a Geoecologia em duas fases temporais: entre 1997 e 2010 e a partir de 2011, ao qual se associa, ainda, a contribuição de grupos de pesquisa devidamente cadastrados no $\mathrm{CNPq}$ e o fortalecimento da pós-graduação no Brasil, com diferenciação na participação das regiões brasileiras (Figura 2).

A partir de 1997 há crescimento de pesquisas, ora com baixa frequência, em alguns anos, ora com ampliação de defesas (Figura 2). Em 2001 e 2008 não consta nenhuma pesquisa defendida dentro da temática abordada, e a partir de 2011 há expressivo crescimento das pesquisas, especialmente em nível de mestrado. A avaliação da contribuição das instituições onde as pesquisas foram desenvolvidas indica uma diferenciação temporal e quantitativa entre as instituições (Figura 3).

Dentro ainda do primeiro recorte temporal (até 2010), as instituições e programas de pós- graduação existentes na Região Sudeste concentraram 20\% (de todo o universo amostral de pesquisas) com forte contribuição da Universidade Federal do Rio de Janeiro (13 pesquisas), seguida pela Universidade de São Paulo (4 pesquisas); e pela Universidade Estadual do Rio de Janeiro (1 pesquisa), Universidade Estadual Paulista "Júlio de Mesquita Filho" (UNESP - Rio Claro) e Universidade Estadual de Campinas (Unicamp), que apresentaram 2 pesquisa cada. A UFRJ tem importante contribuição nesse período de desenvolvimento da Geoecologia das Paisagens no Brasil, em parte pela forte vinculação de teses e dissertações na aplicação da Geoecologia para o planejamento, assim como na formação de pesquisadores na temática. 


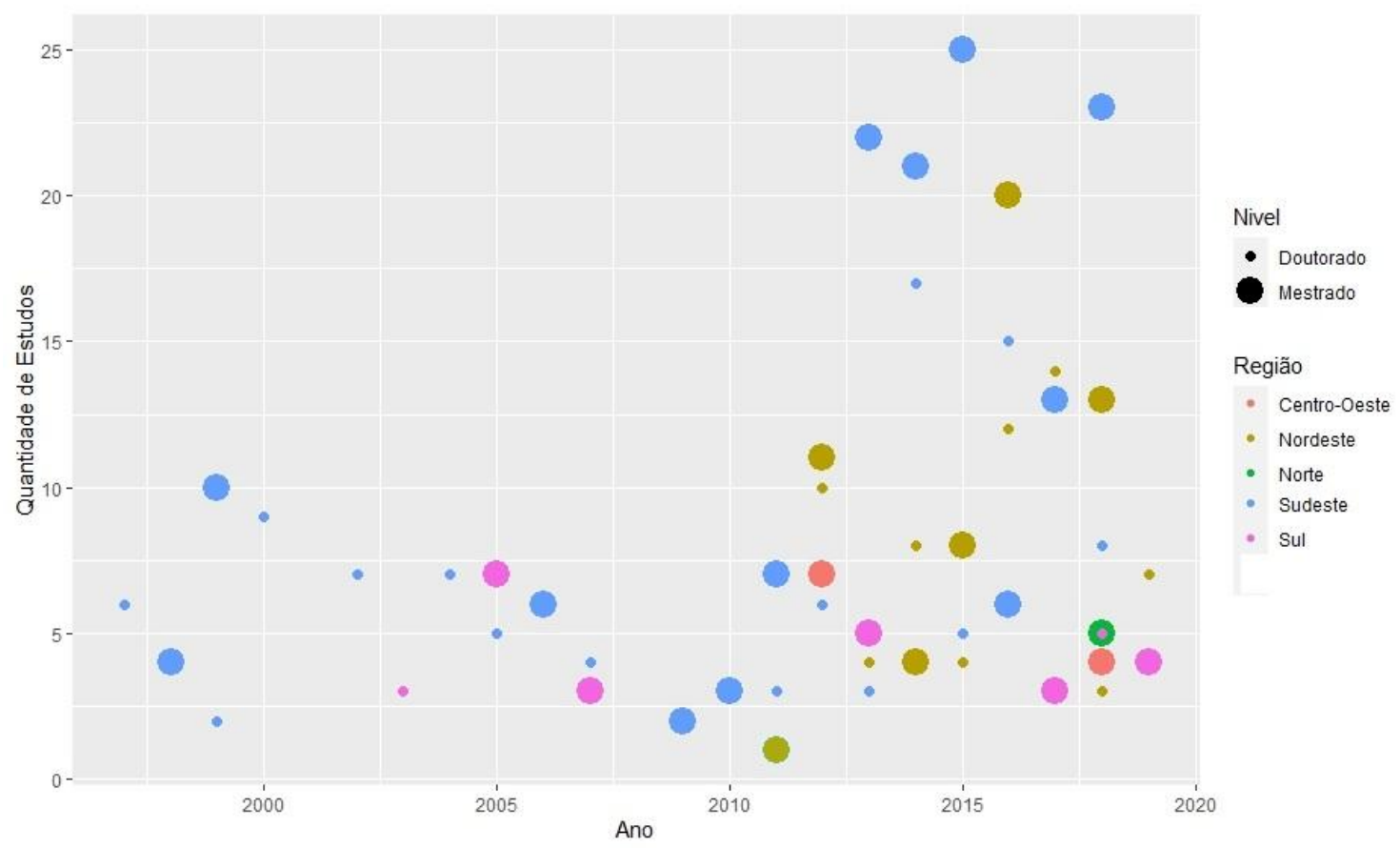

Figura 2: Distribuição das Defesas na área de Geoecologia na Pós-Graduação por ano.

Fonte: Bases de dados. Organização: Autores, 2020.

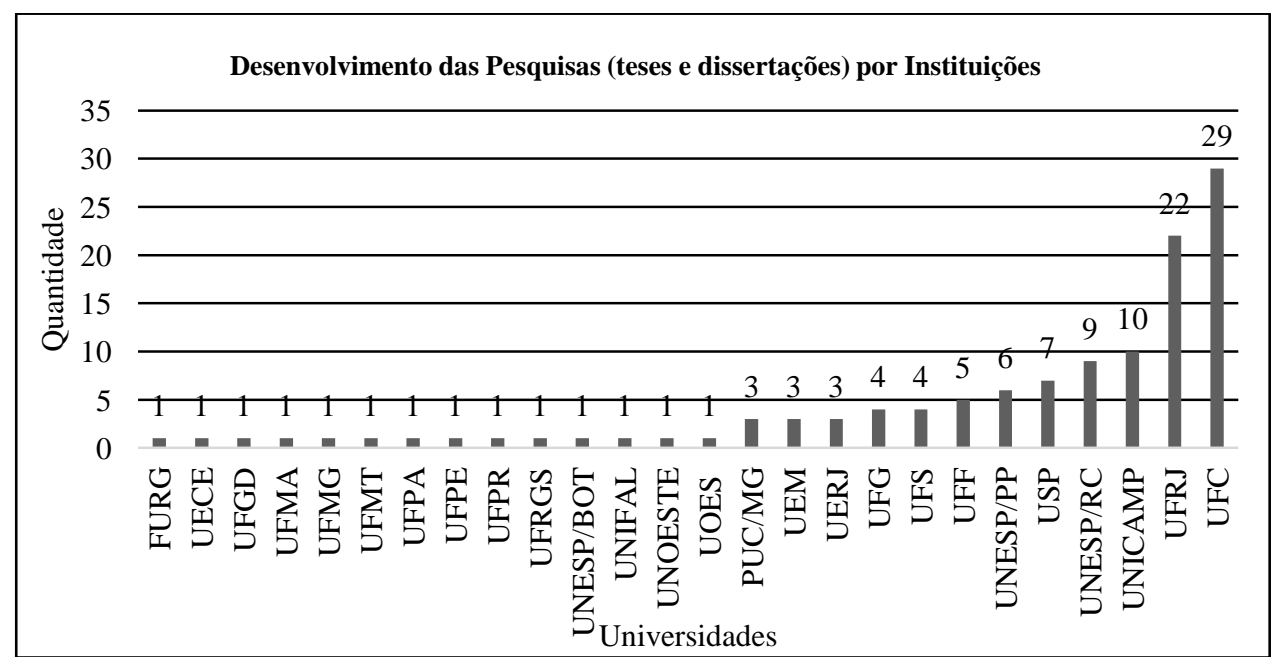

Figura 3: Quantitativo do desenvolvimento das pesquisas (teses e dissertações) por Instituições.

Fonte: Bases de dados. Organização: Autores, 2020.

Na Região Sul, a contribuição para a temática é da Universidade Federal de Santa Catarina (UFSC) e da Universidade Estadual de Maringá (UEM). Na UFSC, a pesquisa pioneira foi uma tese de doutorado que tratava da Cartografia Geoecológica para gestão e planejamento territorial e desenvolvida no programa de Pós-Graduação em Engenharia Civil. Na UEM, as pesquisas adotaram o termo "geoecológico" na associação relativa à identificação e caracterização de unidades de paisagem para planejamento em bacias hidrográficas.

Os dados indicam que a partir de 2011 , as pesquisas sobre a temática apresentam crescimento e constância acima de 5 publicações e defesas ao ano, com certa diversificação de Programas de PósGraduação (PPG), com contribuição dos PPGs de Ciências Ambientais (8 pesquisas); Geociências e Engenharia Agrícola (1 pesquisa em cada PPG), mas, a dominância ainda é garantida em PPGs da Geografia (104 pesquisas).

As universidades da Região Sudeste, no segundo recorte temporal, ainda apresentaram a maior concentração de pesquisa defendidas (39\% da amostragem total), mas se deve considerar que a região concentra o maior número de programas de Pós-Graduação em Geografia no Brasil. No entanto, nesse segundo recorte temporal, ao contrário da UFRJ, a UNESP (Botucatu, Rio Claro e Presidente Prudente) e UNICAMP passam a se destacar com maior número de pesquisas desenvolvidas (21 pesquisas ao total). 
Entretanto, neste segundo recorte temporal (a partir de 2011), observa-se que as pesquisas se deslocaram para outras regiões brasileiras e outros programas de pós-graduação. A escola geográfica cearense, em parceria com a escola cubana, tem forte e importante contribuição para dispersão dos estudos da Geoecologia das Paisagens no território brasileiro (BARBOSA; GONÇALVES, 2014), pois a partir da primeira defesa (em 2011), em pesquisa de mestrado, vem, desde então, mantendo-se anualmente uma forte contribuição em teses e dissertações sob a temática. A UFC, representada nos PPGs de Ciências Ambientais e de Geografia, responde sozinha por $24 \%$ da amostragem de pesquisas de pós-graduação.

O destaque para a UFC pode se vincular a existência do Grupo de Pesquisa "Geoecologia da Paisagem e Educação Ambiental Aplicada", que agrega os pesquisadores de referência no uso da abordagem da Geoecologia das Paisagens com referência aos estudos do século XIX propostos por Humboldt, Lamonosov e Dokuchaev, e na Geografia da Paisagem de Carl Troll, que tem como fundamento teórico a concepção de geossistema de Sochava (BARBOSA; GONÇALVES, 2014), que visa o planejamento territorial e ambiental. A partir de 2011 a temática vem sendo amplamente discutida na geografia brasileira, principalmente por autores como Cavalcanti (2014), Silva e Rodriguez; Silva e Cavalcanti (2013) e Rodriguez e Silva (2013a e 2013b).

Na Região Centro-Oeste, as primeiras pesquisas da abordagem geoecológica também se iniciam em 2011, em uma pesquisa de doutorado defendida na Universidade Federal de Goiás, que integrou a abordagem geográfica com a abordagem ecológica, com fins de planejamento ambiental de paisagens. Em 2012, há um registro de pesquisa de mestrado, dentro da mesma perspectiva temática. No entanto, somente a partir de 2017 são defendidas novas pesquisas em nível de mestrado, sendo, neste ano, 1 pesquisa para a Universidade Federal de Grande Dourados e outra na Universidade Federal de Goiás. E em 2018, 1 defesa para a Universidade Federal do Mato Grosso, e em 2019 outra defesa para a Universidade Federal de Goiás.

A Região Norte só foi indicada nos dados do banco de teses e dissertações da Capes no ano de 2018, com 1 pesquisa de mestrado. A Região Sul desenvolveu, dentro desse segundo recorte temporal, 5 pesquisas, sendo 1 em 2013 na Universidade Federal do Paraná; e as demais a partir 2017, na Universidade Estadual de Maringá (1 pesquisa), e na Universidade Federal do Rio Grande do Sul (2 pesquisas).

A avaliação da influência dos grupos de pesquisa no desenvolvimento de pesquisas acerca das Geoecologia das Paisagens (Tabela 1) também permite perceber dois intervalos temporais até 2010. A base do CNPq indicou a existência de 8 grupos liderados por pesquisadores também vinculados a pós-graduação, presentes especialmente nas regiões Norte, Nordeste e Sudeste, que apresentam, claramente, a Geoecologia como linha de pesquisa associada ao zoneamento territorial. Após 2011, observa-se crescimento no número de grupos de pesquisa registrados, inclusive com registro na região Centro-Oeste, e uma diversificação de linhas e associação da Geoecologia com a Biogeografia.

Entretanto, considerando a correlação entre os grupos de pesquisa e os pesquisadores, orientadores e orientandos de grupos presentes no Nordeste como Geoecologia da Paisagem e Educação Ambiental Aplicada (UFC) e GEOPLAN - Geoecologia e Planejamento Territorial (UFS), tem maior vinculação às pesquisas avaliadas e enquadradas na presente análise. A socialização dos princípios teóricos e metodológicos da Geoecologia das Paisagens estaria ocorrendo com maior intensidade nos grupos do Nordeste, influenciando na divulgação e desenvolvimento de pesquisas, permitindo inclusive novas reflexões e abordagens.

$\mathrm{Na}$ análise das palavras-chave das dissertações e teses foram identificadas 383 utilizadas como indexadores das pesquisas e da temática. Borba et al., (2012) destaca a importância da comunicação das terminologias usadas como palavras-chaves para estrutura textual e identificação de conceitos, mas considera, ainda, que as palavras-chave marcariam o "território" da pesquisa.

Assim, após o processo de padronização adotado e apresentado na metodologia, constata-se que o termo "Geoecologia" e seus associados (Geoecologia da Paisagem, Geoecologia das Paisagens, Funções Geoecológicas, Estado Geoecológico) correspondem a $27 \%$ da amostragem, seguido por indexadores envolvendo o grupo das Geotecnologias com temáticas relativas a Cartografia, Geoprocessamento e modelagens de riscos e vulnerabilidades (17\% da amostragem). As pesquisas destacam a concentração de estudos em unidades de conservação com aplicação de estratégias de recuperação e reabilitação ambiental, assim como as localidades pesquisadas (bairros, municípios, comunidades), respectivamente com 14 e 13\%; a associação de indexadores relativos ao método de análise integrada correspondem a $11 \%$, assim como indexadores de abordagens diversas, o que destaca o caráter interdisciplinar da Geoecologia (9\%). O destaque para as bacias hidrográficas tem menor percentual (7\%) (Figura 4), mas é o termo mais utilizado nos títulos. 
Tabela 1: Grupos de pesquisa cadastrados no Diretório de Grupos de Pesquisa no Brasil

\begin{tabular}{|c|c|c|c|c|}
\hline Região & Instituição & Grupo & $\begin{array}{l}\text { Criação } \\
\text { do Grupo }\end{array}$ & Linha De Pesquisa \\
\hline Nordeste & UFS & $\begin{array}{l}\text { Geoplan - Geoecologia e } \\
\text { Planejamento Territorial }\end{array}$ & 2004 & Geoecologia/Fitogeografia Aplicada \\
\hline Norte & UFMA & Geografia Física da Amazônia & 2006 & Geoecologia \\
\hline Sudeste & UFSCar & Paleoecologia e Paleoicnologia & 2006 & Geoecologia \\
\hline Sudeste & UNICAMP & $\begin{array}{l}\text { A Dinâmica das Paisagens em } \\
\text { Ambientes Costeiros }\end{array}$ & 2007 & $\begin{array}{l}\text { Zoneamento Geoambiental de Áreas } \\
\text { Costeiras }\end{array}$ \\
\hline Nordeste & UFC & $\begin{array}{l}\text { Geoecologia da Paisagem e } \\
\text { Educação Ambiental Aplicada }\end{array}$ & 2008 & Geoecologia da Paisagem \\
\hline Nordeste & UFCG & $\begin{array}{l}\text { Gestão e Ordenamento Ambiental - } \\
\text { GEOAMB }\end{array}$ & 2010 & $\begin{array}{l}\text { Estudos Ambientais, Ordenamento do } \\
\text { Território e Geoecologia }\end{array}$ \\
\hline Sudeste & $\mathrm{UFF}$ & $\begin{array}{l}\text { Núcleo de Estudos e Planejamento } \\
\text { Em Hidrogeografia - NEPH }\end{array}$ & 2010 & $\begin{array}{l}\text { Geoecologia da Paisagem e Conservação } \\
\text { dos Recursos Hídricos }\end{array}$ \\
\hline Norte & UFPA & $\begin{array}{l}\text { Grupo de Estudo Paisagem e } \\
\text { Planejamento Ambiental - } \\
\text { GEPPAM }\end{array}$ & 2011 & $\begin{array}{l}\text { Geoecologia da Paisagem e Impactos } \\
\text { Socioambientais }\end{array}$ \\
\hline Sudeste & $\mathrm{UFF}$ & $\begin{array}{l}\text { Laboratório de Geografia Física } \\
\text { (Lagef) }\end{array}$ & 2011 & Geoecologia da Paisagem \\
\hline Nordeste & UPE & $\begin{array}{l}\text { Grupo de Pesquisa em Sociedade e } \\
\text { Natureza do Vale do São Francisco }\end{array}$ & 2013 & $\begin{array}{l}\text { Monitoramento Ambiental e } \\
\text { Geotecnologia }\end{array}$ \\
\hline Sul & UFFS & $\begin{array}{l}\text { Núcleo de Estudos e Pesquisas } \\
\text { sobre Região, Urbanização }\end{array}$ & 2014 & $\begin{array}{l}\text { Dinâmicas Socionaturais e Transformações } \\
\text { das Paisagens }\end{array}$ \\
\hline Nordeste & UFRN & $\begin{array}{l}\text { Trópikos - Biogeografia de } \\
\text { Ecossistemas Tropicais }\end{array}$ & 2014 & $\begin{array}{l}\text { Biogeografia e Geoecologia da Paisagem/ } \\
\text { Geoecologia de Áreas Úmidas }\end{array}$ \\
\hline Sul & UFSM & $\begin{array}{l}\text { Pangea - Patrimônio Natural, } \\
\text { Geoconservação e Gestão da Água }\end{array}$ & 2015 & Paisagem e Patrimônio Natural \\
\hline $\begin{array}{l}\text { Centro- } \\
\text { Oeste }\end{array}$ & UFMS & $\begin{array}{l}\text { Estudos Geoecológicos nas Bacias } \\
\text { Hidrográficas do Paraguai/Paraná }\end{array}$ & 2016 & Biogeografia e Geoecologia da Paisagem \\
\hline Nordeste & UNIVASF & $\begin{array}{l}\text { Gema - Geografia, Ecologia } \\
\text { Espacial e Modelagem Ambiental }\end{array}$ & 2016 & Ecologia Espacial e Geoecologia \\
\hline Norte & UFPA & $\begin{array}{l}\text { Grupo de Estudos Análise de } \\
\text { Paisagens Amazônicas - GEAPA }\end{array}$ & 2018 & Planejamento e Gestão Ambiental \\
\hline Sudeste & UFRRJ & $\begin{array}{l}\text { Grupo de Estudos de Biogeografia } \\
\text { e Dinâmicas da Paisagem }\end{array}$ & 2018 & Biogeografia e Geoecologia da Paisagem \\
\hline Nordeste & UNIVASF & $\begin{array}{l}\text { NEPST- Núcleo de Estudos das } \\
\text { Paisagens Semiáridas Tropicais }\end{array}$ & 2018 & Biogeografia e Geoecologia da Paisagem \\
\hline Norte & IDSM & $\begin{array}{l}\text { Análise Geoespacial, Ambiente e } \\
\text { Territórios Amazônicos - } \\
\text { Geoespacial }\end{array}$ & 2019 & Estruturas e Processos Geoecológicos \\
\hline Sudeste & UFRRJ & $\begin{array}{l}\text { Laboratório Integrado de Geografia } \\
\text { Física Aplicada }\end{array}$ & 2019 & Biogeografia e Geoecologia da Paisagem \\
\hline
\end{tabular}

A avaliação dos temas desenvolvidos nas teses e dissertações comprovam o caráter interdisciplinar da Geoecologia, conforme a região, instituição de ensino e, ainda, orientador. A análise dos temas centrais dos trabalhos indica forte diferenciação na aplicação da Geoeocologia das Paisagens entre as instituições, mas há vinculação das pesquisas com fins de planejamento, zoneamento e análise de dinâmicas de ocupação. 


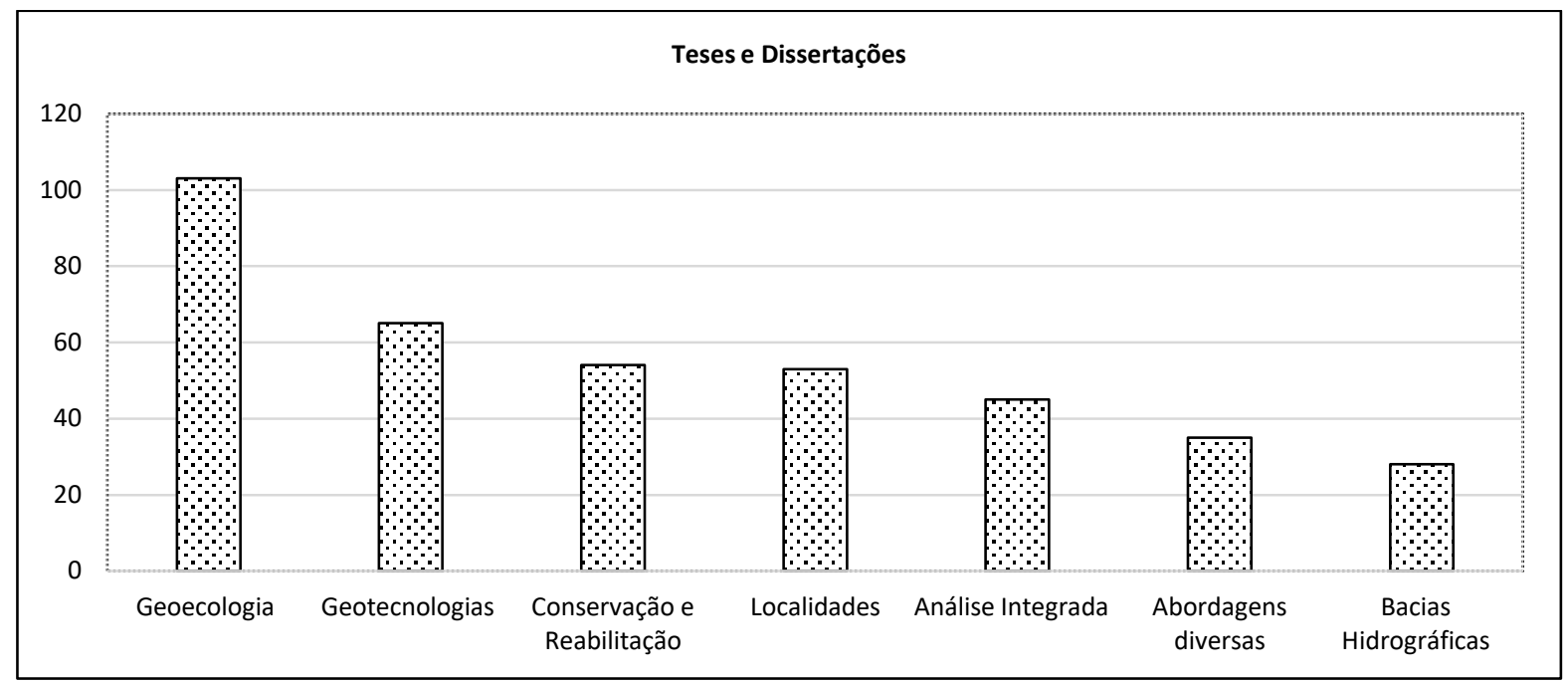

Figura 4: Distribuição das palavras-chave por agrupamentos - teses e dissertações. Fonte: Autores, 2020.

Os estudos conduzidos na UFC, UNICAMP e UNESP/RC apresentam forte concentração de pesquisas com proposições e análises do planejamento e zoneamento, associadas a Geoecologia, enquanto a UFRJ destaca a associação e contribuição metodológica das Geotecnologias para modelagens de Riscos a Incêndios dentro da abordagem sistêmica da Geoecologia. Na UFG há forte vinculação para análise da estrutura da paisagem com foco em processos de fragmentação, aproximando-se da abordagem proposta pela Ecologia das Paisagens.

Embora, nas palavras-chave o indexador "bacia hidrográfica" tenha apresentado baixa participação diante dos outros indexadores, a preferência pelo uso de bacias hidrográficas como ambiente de análise tem destaque em todas as regiões e instituições.

\subsection{Análise dos artigos}

Do total de artigos publicados em diferentes revistas científicas e localizados em distintas bases de dados, observa-se também a existência de dois recortes temporais (até 2010 e pós 2011): até 2005 as publicações se mantém com média de uma publicação por ano, em 2007 há crescimento no número de publicações, mas é a partir de 2011 que a média de publicação apresenta crescimento expressivo (Figura 5). Dentro do recorte temporal, observa-se ausência de publicações nos anos de 2003 e 2006.

A publicação localizada mais antiga é do ano de 2000 e corresponde a um trabalho publicado na revista Ensaios e Ciências, que apresenta uma proposta de Zoneamento Geoecológico a partir de Unidades de Paisagem em região cárstica no Mato Grosso do Sul. O artigo indica que os dados se vinculam a pesquisa de mestrado defendida em 1998, na Universidade para o Desenvolvimento do Estado e da Região do Pantanal (UNIDERP). Este trabalho, no entanto, não consta na base de dados e, portanto, não foi analisado na seção anterior, pois ele não atendeu os critérios de seleção no BDBTD e no catálogo da Capes. O mesmo não foi encontrado em busca livre, isto comprova, como já exposto, os problemas relacionados as bases de dados e lacunas relativas à disponibilização de teses e dissertações defendidas anterior a adoção de repositórios digitais.

O comportamento do aumento de pesquisas a partir de 2011 também constatado para as teses e dissertações, também é observado para os artigos, e, embora verifique-se expressivo número de artigos que se dedicam a apresentar a abordagem teórica da Geoecologia das Paisagens, prevalecem pesquisas de aplicação da teoria e metodologia a bacias hidrográficas e/ou municípios, predominantemente na Região Sudeste do Brasil. Ainda que as revistas selecionadas para publicação não apresentem indexação internacional (ausência de JCR é de 100\%), as publicações contemplam os periódicos de todas as regiões brasileiras, nas distintas áreas de atuação da Geografia e em classificação pelo Qualis-Capes. 


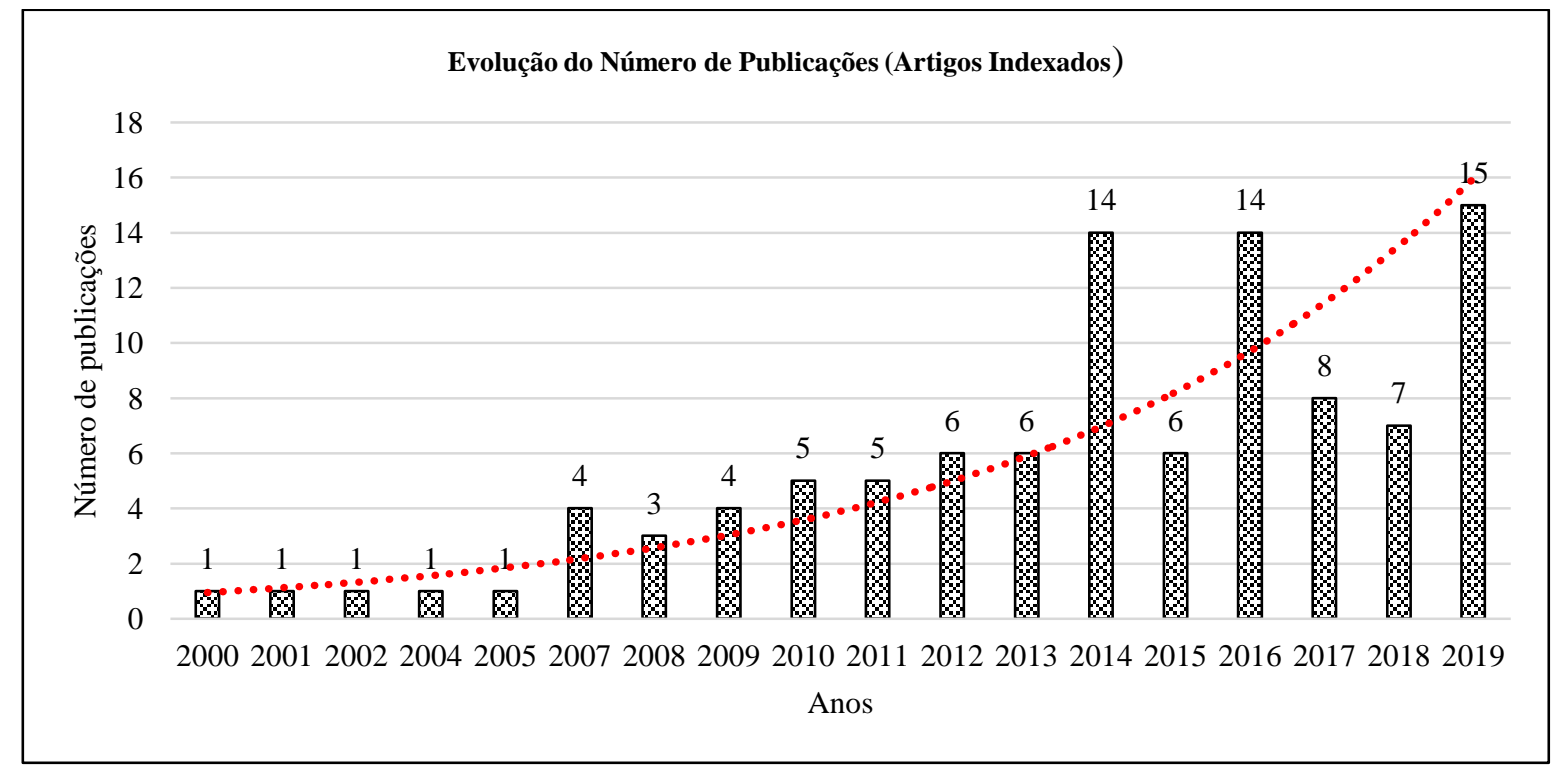

Figura 5: Evolução do Número de Publicações. Fonte: Autores, 2020.

A Revista Brasileira de Geografia Física disponibilizou, no ano de 2019, uma sessão específica para trabalhos de Geoecologia, o que cria expectativa de aumento de publicações nos próximos anos neste periódico. Considerando o universo de artigos avaliados, destaca-se o número de publicações na revista Sociedade \& Natureza (10 artigos), seguida pela revista Mercator (8 artigos), que correspondem a periódicos do extrato superior do Qualis-Capes.

$\mathrm{Na}$ análise das palavras-chave dos artigos foram identificadas 301 utilizadas como indexadores das pesquisas e da temática (Figura 6).

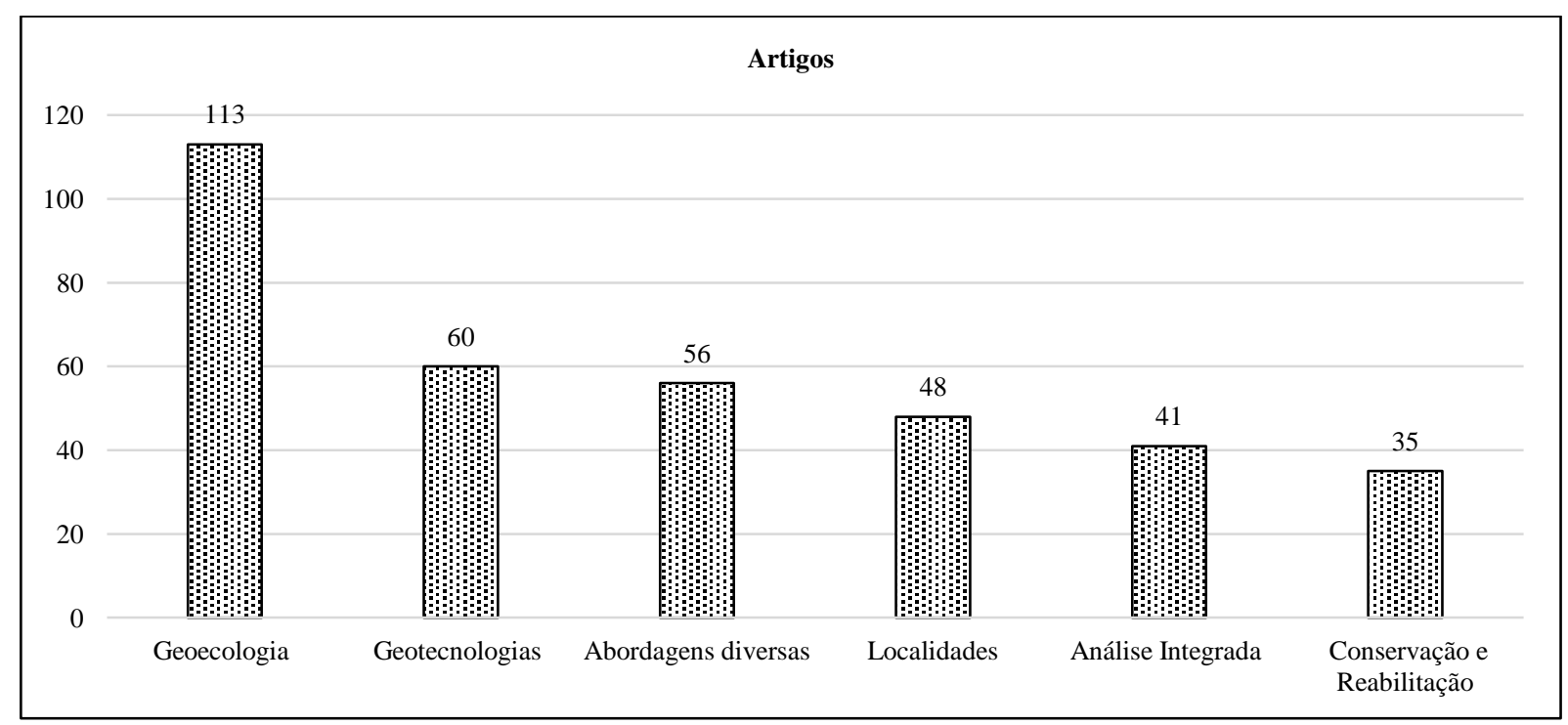

Figura 6: Distribuição das Palavras-chave por Agrupamentos - Artigos. Fonte: Autores, 2020.

Assim como nas teses e dissertações, as pesquisas exercem forte relação com indexador "Geoecologia" e seus associados (30\% de frequência) e ainda mantém a relação com "Geotecnologias" (16\%), mas o grupo de abordagens diversas tem maior destaque que os outros grupos.

O financiamento das pesquisas por agências federais como CNPq, Capes e fundações estaduais de pesquisa foram indicados em apenas 18 artigos. O predomínio é de publicações que não indicaram as fontes de financiamento ( 83 artigos $-82 \%$ ). A indicação das fontes de financiamento não corresponde a um item obrigatório a ser informado para a periódico responsável pela publicação, mas avaliando a correlação das publicações com as pesquisas acadêmicas constata-se que apenas 2 artigos com vínculo às pesquisas de pósgraduação atestaram que o financiador correspondeu ao CNPq e Capes. Como as pesquisas em nível de pós- 
graduação na Geografia comumente são subsidiadas com bolsas de pesquisa, por algum órgão de fomento, tal informação deveria constar na publicação da pesquisa no periódico.

Embora a temática de Geoecologia tenha apresentado um aumento no número de publicações, $74,7 \%$ dos artigos identificados não tem nenhuma correlação com as pesquisas acadêmicas de teses e doutorados, mesmo após o ano de 2011 (Tabela 2).

Tabela 2: Vinculação das Publicações à Pós-Graduação e com Grupos de Pesquisa

\begin{tabular}{ccccc}
\hline Ano de Publicação & $\begin{array}{c}\text { Sem vínculo } \\
\text { com a Pós }\end{array}$ & $\begin{array}{c}\text { Com vínculo } \\
\text { com a Pós }\end{array}$ & $\begin{array}{c}\text { Sem vínculo com o } \\
\text { Grupo de Pesquisa }\end{array}$ & $\begin{array}{c}\text { Com vínculo com o } \\
\text { Grupo de Pesquisa }\end{array}$ \\
\hline 2000 & 1 & & 1 & \\
2001 & 1 & & 1 & 1 \\
2003 & 1 & & 1 & \\
2004 & 1 & 1 & 1 & \\
2005 & & & 3 & \\
2007 & 3 & 1 & 2 & 2 \\
2008 & 2 & 3 & 2 & 1 \\
2009 & 1 & 1 & 4 & 4 \\
2010 & 4 & 1 & 1 & 3 \\
2011 & 3 & 1 & 1 & 6 \\
2012 & 4 & & 3 & 2 \\
2013 & 6 & 2 & 8 & 2 \\
2014 & 14 & 6 & 8 & 1 \\
2015 & 4 & 3 & 6 & 8 \\
2016 & 8 & 4 & 6 & \\
2017 & 5 & 1 & 7 & \\
2018 & 3 & & & \\
2019 & 14 & & & \\
\hline
\end{tabular}

Fonte: Autores, 2020.

Tal avaliação permite inferir que as publicações sobre a temática ocorrem isoladas, o que se comprova com a avaliação dos autores aos grupos de pesquisa sobre a temática, e indica que as pesquisas publicadas apresentam baixo vínculo aos grupos de pesquisa.

Dentro do recorte temporal avaliado, a média de publicações de teses, dissertações e artigos está em torno de 5,5 publicações anuais. Índices que poderiam ser considerados baixos ou medianos, caso comparados com outras pesquisas, no entanto, deve-se recordar do caráter interdisciplinar da disciplina.

A análise dos dados indica que as pesquisas em nível de teses e dissertações e dos artigos em pesquisas se dedicam a avaliações integradas da paisagem com fins de planejamento com adoção de estratégias e metodologias de zoneamento territorial, apontam a tendência de organização da disciplina para essa tipologia de análise científica. Pesquisadores formados dentro da abordagem da Geoecologia estão muito recentemente inseridos no papel de docentes nas universidades e avaliando a tendência de pesquisas/orientações em andamento (mas fora do recorte temporal adotado nesta pesquisa), a expectativa é de ampliação e maior consolidação.

\section{Considerações finais}

A Geoecologia das Paisagens tem um caráter multidisciplinar e interdisciplinar embasada em princípios sistêmicos e integrados da paisagem com abordagens que visam a sustentabilidade, o planejamento e a gestão ambiental para a prevenção, mitigação e recuperação de degradações ambientais. Essas são as abordagens seguidas nas pesquisas desenvolvidas no Brasil em programas de pós-graduação e ainda nas publicações em periódicos indexados, como constada na análise cienciométrica.

A coleta de dados aponta a existência de dois recortes temporais (até 2010 e após 2011), que indicam a diversificação de pesquisas nas regiões brasileiras, com forte destaque para instituições de ensino superior e de pesquisadores vinculados às regiões Sudeste e Nordeste, que apresentam, ainda, vinculações de abordagens distintas, pois as pesquisas na Região Nordeste estão ligadas a escola geográfica cearense, e 
abordam diretamente o uso da Geoecologia para o planejamento territorial e ambiental, enquanto a Região Sudeste, vinculadas a escola geográfica carioca, tem forte associação ao geoprocessamento para análises integradas em modelagens preditivas de risco a incêndios, e a escola geográfica paulista com abordagem para o zoneamento. As pesquisas desenvolvidas nas demais regiões também tem associação com planejamento, mas são crescentes e tem associação com análise de impactos ambientais.

Infere-se que a associação da Geoecologia a estudos da Biogeografia, assim como outras temáticas relativas à análise integrada e análises ambientais, possa ter influenciado na amostragem de pesquisas apresentadas neste artigo, uma vez que a análise selecionou publicações com abordagens de análise da paisagem para o planejamento.

$\mathrm{Na}$ análise dos artigos, além de reduzida vinculação dos pesquisadores a grupos de pesquisa sobre a temática, também se constatou baixa conexão a pesquisas desenvolvidas na pós-graduação, o que indica o uso da abordagem teórica e metodológica em pesquisas paralelas ao objeto em investigação na pósgraduação. No entanto, as pesquisas estão apenas internalizadas em periódicos nacionais, pois mesmo que exista uma concentração de artigos publicados em revistas pertencentes ao estrato superior do Qualis-Capes, elas não têm alcance internacional nas bases usuais de pesquisa.

Observou-se discreta influência dos grupos de pesquisas, existentes na base de dados do CNPq. No desenvolvimento das pesquisas, a maior vinculação às publicações (tese, dissertações e artigos) é exercida pelo Grupo de Pesquisa Geoecologia da Paisagem e Educação Ambiental Aplicada da UFC, que contempla pesquisadores com publicações responsáveis pela divulgação da abordagem no território brasileiro.

O universo de publicações relativos a teses, dissertações e artigos avaliados permite a elaboração de um banco de dados de divulgação das pesquisas já desenvolvidas no Brasil, e mesmo com as limitações e dificuldades na seleção do material em todas as bases utilizadas para seleção de obras, o número amostral foi suficiente para as análises cienciométricas.

\section{Referências}

BARBOSA, L.G.; GONÇALVES, D. L. A paisagem em geografia: diferentes escolas e abordagens. In: Élisée, Rev. Geo. UEG - Anápolis, v.3, n.2, 92-110, 2014.

BARROS, L. L. Aplicações da geoecologia da paisagem no planejamento ambiental e territorial dos parques urbanos brasileiros. Revista Geográfica de América Central. Número Especial EGAL, Costa Rica II Semestre, 1-14, 2011.

BITTENCOURT, L.A.F.; PAULA, A. de. Análise Cienciométrica de Produção Científica em Unidades de Conservação Federais Do Brasil. Enciclopédia Biosfera, Centro Científico Conhecer - Goiânia, v.8, n.14, 2012.

BORBA, D. dos S.; VAN DER LAAN, R. H.;CHINI, B. Ros. Palavras-chave: convergências e diferenciações entre a linguagem natural e a terminologia. Perspect. ciênc. inf. [online]. v.17, n.2, 26-36, 2012.

BORNMANN, L. LEYDESDORFF, L. Scientometrics in a changing research landscape: bibliometrics has become an integral part of research quality evaluation and has been changing the practice of research. EMBO Rep. v.15, n.12,1228-1232, 2014

CARDOSO, A. M. P. Educação para a informação: desafios contemporâneos para a Ciência da Informação. Revista de Ciência da Informação, v. 3, n. 5, 1-8, 2002.

CAVAlCANTI, L. C. de S. Cartografia de Paisagens: fundamentos. São Paulo: Oficina de Textos, 2014.

FARIA, A. H. P. de; ALVES, D. F. C. Caderno de Geografia: análise bibliométrica, espacial e de conteúdo do acervo de 1990 a 2016. Caderno de Geografia, v.26, número especial 1, 2016.

JANISE, D.; LEONARDO, S. A paisagem e o geossitema como possibilidade da expressão do espaço sócioambiental rural. Confins, n. 1, 2007. 
LEYDESDORFF, L. The Challenge of Scientometrics - The development, measurement, and selforganization of scientific communications. Universal-Publishers, Amsterdam, 3th edition, 2004, 355p

PARRA, M.R.; COUTINHO, R.X.; PESSANO, E.F.C. Um Breve Olhar sobre a Cienciometria: Origem, Evolução, Tendências e sua Contribuição para o Ensino de Ciências. Contexto \& Educação, v.34, n.107, 2019.

RODRIGUEZ, J. M. M., SILVA, E. V.; CAVALCANTE, A. P. B. Geoecologia das Paisagens: uma visão geossistêmica da análise ambiental. Fortaleza: Edições UFC, 2013.

RODRIGUEZ, J. M. M.; SILVA, E. V. da. A classificação das paisagens a partir de uma visão geossistêmica. Revista Mercator. v. 1, n. 1, 2, 95-112, 2002.

RODRIGUEZ, J. M. M.; SILVA, E. V. Para una interpretação epistemológica de la Geografia a partir de la Dialéctica. Revista Mercator. v 4, n. 9, 55- 68, 2006.

RODRIGUEZ, J. M. M.; SILVA, E. V. Planejamento e gestão ambiental: subsídios da Geoecologia das Paisagens e da Teoria Geossistêmica. Fortaleza: Edições UFC, 2013a.

RODRIGUEZ, J. M. M.; SILVA, E. V. Educação Ambiental e Desenvolvimento Sustentável: problemática, tendências e desafios.3 ed.- Fortaleza: Expressão Gráfica e Editora, 2013b.

SILVA FILHO, J. N. DA. Volume de publicações científicas sobre Educação Ambiental na Base SciELO Brasil: um estudo de cienciometria. Revista Brasileira de Educação Ambiental (RevBEA), v. 14, n. 1, 207-221, 2019.

SIQUEIRA, M. N.; CASTRO, S.S.; FARIA, K.M.S. de. Geografia e Ecologia da Paisagem: Pontos para Discussão. Revista Sociedade \& Natureza, v. 25, n. 3, 557-566, 2013.

SPINAK, E. Indicadores cienciométricos. Revista Ciência da Informação, Brasília, v. 27, n. 2, 1998.

TAGUE-SUTCKIFFE, J. An introduction to informetrics. Information Processing \& Management, v. 28, n. 1, p. 1-3, 1992.

VANTI, N. Da bibliometria à webometria: uma exploração conceitual dos mecanismos utilizados para medir o registro da informação e a difusão do conhecimento. Ciência da Informação, v. 31, n. 2, p. 152-162, 2002.

VINKLER, P. Composite scientometric indicators for evaluating publication of research institutes. Scientometric, v. 68, n.3, p. 629-642. 2006.

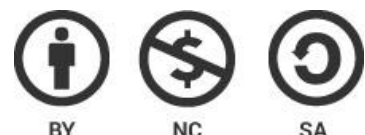

Este artigo é distribuído nos termos e condições do Creative Commons Attributions/AtribuiçãoNãoComercial-CompartilhaIgual (CC BY-NC-SA). 